\title{
The Development of Low Cost Electronic Books for the Blind
}

\author{
Adisorn Sirikham and Yuwadee Sae-Ear
}

\begin{abstract}
The objective of this research is to develop low cost mobile electronic books for the blind and to evaluate their satisfaction with the electronic books. Instruments used for this study consisted of: 1) Mobile electronic books, 2) Evaluation forms for the target group consisting of 30 people who are blind. The research determined that: 1) The quality of electronic books that have been invented for the blind have an average value of 4.25 which is satisfactory 2 ) The level of satisfaction with these books by blind people showed an average of 4.18 which is a high level of satisfaction. Therefore, the development of the format for these mobile electronic books can be used for further study to gain more knowledge.
\end{abstract}

Index Terms-Mobile electronic book, audio book, mobile educational media, blind people.

\section{INTRODUCTION}

The blind often have fewer opportunities than other disabled people, whether they be deaf or those who lack mobility. Though blind people may not look different than the other people, they must compensate for their disability. They must develop perception by other means than using their eyes. Hearing or touch is important method of perception for the blind. It is therefore important the technology to enable them to read is created, for both entertainment and educational uses. A current method to enable reading for the blind is through Braille Letters [1].

However, each Braille book is very thick and the thickness of the book represents the price of the book. This is because of the amount of paper being used in publishing Braille letters, (1 normally printed page equals to 3 pages of Braille). The Clorfield Library is responsible for publishing all Braille books in Thailand. These books are distributed to the blind free of charge all over the country; and these books have the same content as the normally printed books used by sighted people [2]. A reading medium that has been invented for the blind is 'Electronic' books. It is a very interesting medium as it also creates convenience for the blind. For this reason the development of electronic books for the blind has significant value. As the blind cannot learn anything through pictures or normally printed pages, they must learn by other methods; the best being the use of sound and hearing. The best method is to record a book or lessons in a tape recorder, which allows blind people to understand better and more easily than by using Braille letters. Tuttle found that blind people studying by using a tape recorder at normal speed,

Manuscript received October 18, 2013; revised December 20, 2013.

A. Sirikham is with the Rajamangala University of Technology Krungthep, Bangkok, Thailand (e-mail: sorn2442@yahoo.com).

Y. Sae-Ear is with the King Mongkut's University of Technology Thonburi, Thailand (e-mail: puthwan@gmail.com). learned twice as fast than by reading Braille and if the recording contained only the necessary parts of the contents or lessons, they would learn three times faster than by reading Braille. This means that for blind students who have high capability they are able to learn up to 275 words per minute and for blind students with normal or below normal capability: 250 words per minute [3].

As mentioned above, we can see that the progress and advancement of electronics today leads to the development of educational media for people who have impaired eye sight including: 1) the Farsighted Program that is used as a Screen Reader [4]; as seen in Fig. 1. 2) speech synthesizer programs 3) screen enlargement programs 4) translation programs that translates English language to Braille 5) Braille translation software 6) bulging program 7) Daisy system book [5] a speaking book on birds in Thailand which is available in book format with both pictures and sounds [5]; as seen in Fig 2.

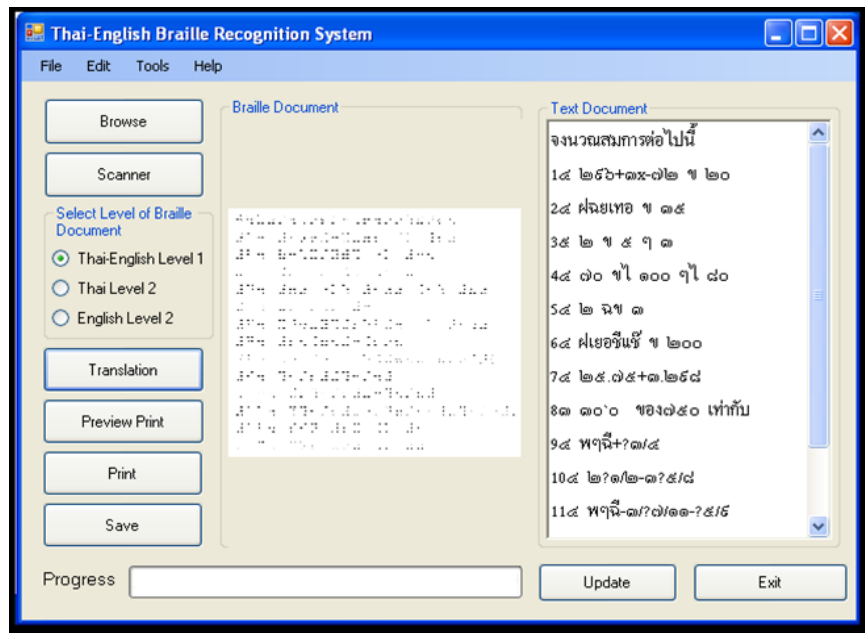

Fig. 1. The Farsighted program [4] (Thai-English OBR system setup).

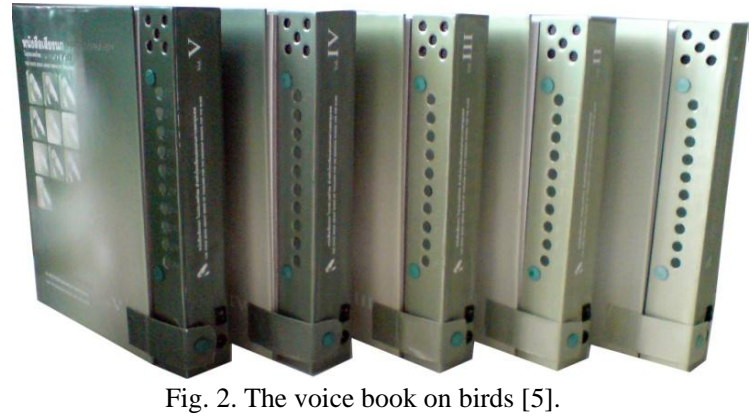

At present; even though there are many educational media available for the blind, in Thailand there is still insufficient electronic media to fulfill demand and the production costs are very high. Some of the existing electronic media available at present are too large and are inconvenient for moving around. Also the content of some texts including the contents 
of lessons, is so outdated that it cannot be further developed, leaving them in a state of decay or actually being incorrect [6].

Due to such problems we can see that the blind should receive educational information using appropriate media to most easily allow them to gain knowledge: either by touch or hearing. Their texts or lessons should be modifiable in in accordance to the learner's level of knowledge and ability.

Therefore, the research presented here, includes the development of mobile electronic books for the blind in which the text and even the sound system can be modified as needed. This research also hopes to develop technology which would stimulate the blind to take more interest in self-learning which can be done at any time and build a good attitude among them to better develop their education in the future.

\section{The Methods of Designing And CREating The EDUCATIONAL MEDIUM}

Borg's and Gall's theories [7] using their methods and development. We studied blind people's needs for books and other educational media as the first step. Observations were made during interviews and data was collected for analysis of problems; concerning the existing books and other media available for the blind. The second step was to invent particular media and test them among the target groups in order to evaluate their quality and the satisfaction of the users.

The research found that Braille books are still the best medium for the blind who can read Braille fluently. However those people that cannot read Braille properly or are beginners, find reading Braille very difficult, causing them to have difficulty understanding the texts, which leads to a lack of confidence and a lack of desire to read or learn; eventually causing them to stop learning completely. The technology currently available for educational materials using sound, are large and cannot be carried around - because they require the use of a computer. For this reason we came up with the idea of developing an electronic book which is a combination between Braille and an electrical sound system specifically made for the blind. This would be a mobile device which can easily be carried anywhere.

\section{The InVEntion OF THE EdUCATIONAL Medium}

This electronic book is the size of an A5 sheet of paper with a monitor in the front along with operating buttons. Upon opening the lid, there will be sound control buttons on the left side and Braille texts on the right as seen in Fig. 3. The sound will be associated with the Braille texts.

The electronic book will consist of 3 main parts which are: 1) the text book 2) the electronic system for sound and 3) the Braille texts.

The front and back covers of the text book are made of acrylic plates with a thickness of $3 \mathrm{~mm}$. to strengthen the book: as this material is to purchase and is easily punctured to attach equipment. The sound control system is attached to the inner side of the front cover with the on-off switches/buttons, a USB socket and an earphone jack. Pieces of resin are attached and shaped for holding the electronics and locking them in position as seen in Fig. 4.

We have chosen the MP3 Wireless FM Modulator for the sound control system as in Fig. 5 in which the sound files will be recorded in an SD memory card in the USB Flash Drive socket. The device will be charged through a Cigarette Lighter Plug in a car. It will also send the sound signal through the Earphone Jack and convert the sound into an FM signal to be able to play sound through the radio player in the car. However; this device has been developed for use in a car only and therefore the source of electricity has to be modified for use with a 9 volt battery. The modifications are made by re-wiring and repositioning of the monitor, control buttons, USB Flash Drive socket and the earphone jack as in Fig. 6.

The texts are divided into two parts which are: the Braille text sheets and the sound files which are recorded from those Braille texts.

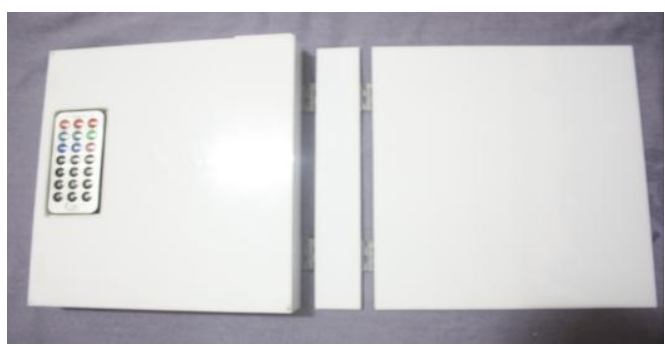

Fig. 3. The proposed electronic book.

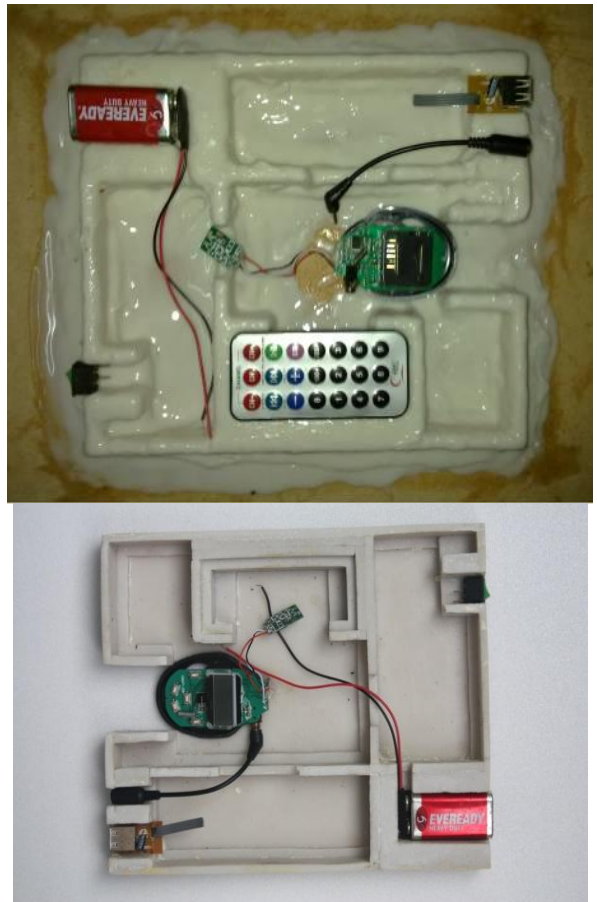

Fig. 4. The resin block molding.

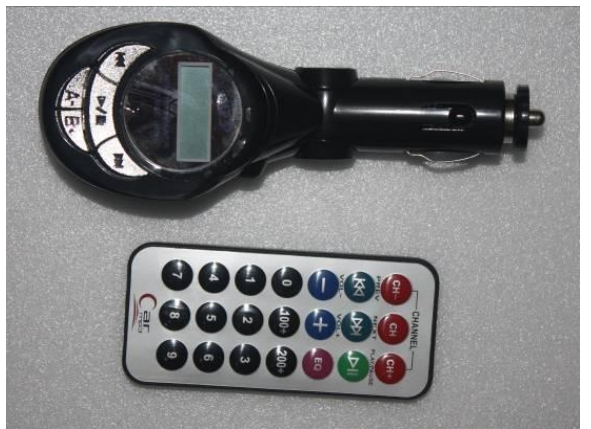

Fig. 5. The MP3 wireless FM modulator. 


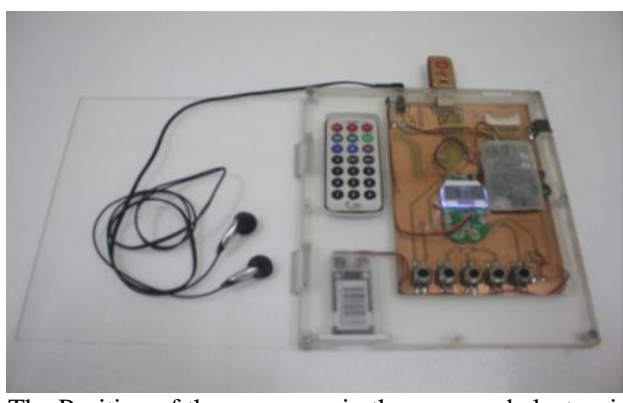

Fig. 6. The Position of the accessory in the proposed electronic book.

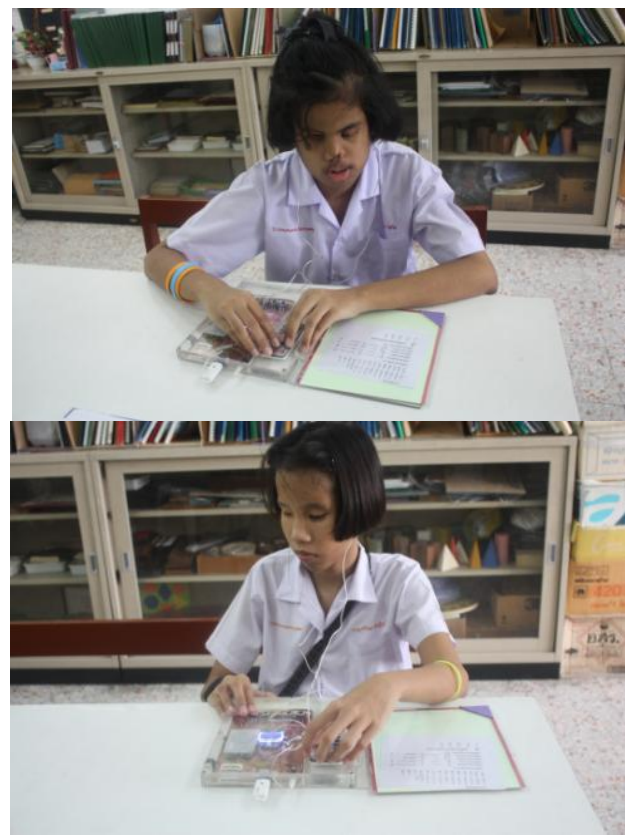

Fig. 7. The blind students used electronic book.

\section{THE EXPERIMENT}

The research on "The Development of Low Cost Electronic Books for the Blind" is an experimental design, with the intention to evaluate satisfaction of blind people with such an electronic book. The research for this experiment consisted of a prototype mobile electronic book and questionnaires regarding the satisfaction of the target group. The devices were distributed randomly to 30 blind students in Bangkok, Thailand and data was then collected from those users to conduct statistical analysis as seen in Fig. 7.

\section{The Evaluation}

From the analysis of the questionnaires received from the 30 people in the target group: the results were calculated to find the averages as in seen Table I and Table II.

Table I shows the results of the quality of the Mobile Electronic Book for blind. The overall results showed a rating of "Good" with the average of the mean equal to 4.25 , with the deviation equal to 0.36 based on the standard of a "Medium" rating.

Table II shows the results of the satisfaction of the Mobile Electronic Book for blind. The overall results showed a rating of "Very Good" with average of the mean equals to 4.18 with the deviation equal to 0.46 based on the based on the standard of a "Medium" rating.
TABLE I: SHOWS THE RESULTS ON THE QUALITY OF THE MOBILE ELECTRONIC BOOK FOR THE BLIND

\begin{tabular}{|c|c|c|c|}
\hline List of evaluation & $\bar{X}$ & S.D. & $\begin{array}{c}\text { Level } \\
\text { of quality }\end{array}$ \\
\hline $\begin{array}{l}\text { 1. Ease of using the text and voice } \\
\text { buttons }\end{array}$ & 4.45 & 0.48 & Good \\
\hline 2. Quality of buttons and switches & 3.23 & 0.37 & Fair \\
\hline 3. Clearness of voice and quality. & 4.71 & 0.33 & Very Good \\
\hline 4. Consumption of power. & 4.08 & 0.27 & Good \\
\hline $\begin{array}{l}\text { 5. The safety of the Mobile Electronic } \\
\text { Book for the blind. }\end{array}$ & 4.78 & 0.36 & Very Good \\
\hline Average & 4.25 & 0.36 & Good \\
\hline
\end{tabular}

TABLE II: SHOWS THE Evaluation OF SATISFACTION OF THE MobiLE ELECTRONIC BOOK FOR THE BLIND

\begin{tabular}{|l|c|c|c|}
\hline \multicolumn{1}{|c|}{ List of evaluation } & $\bar{X}$ & S.D. & $\begin{array}{c}\text { Level } \\
\text { of quality }\end{array}$ \\
\hline $\begin{array}{l}\text { 1. Size and weight of the } \\
\text { medium/device. }\end{array}$ & 4.46 & 0.54 & Good \\
\hline 2. Feature of the medium/ device. & 4.35 & 0.52 & Good \\
\hline 3. Sizes of the buttons. & 3.21 & 0.35 & Fair \\
\hline $\begin{array}{l}\text { 4. Placing and position of buttons and } \\
\text { equipments (SD card, USB ports and } \\
\text { Earphone Jack). }\end{array}$ & 4.42 & 0.42 & Good \\
\hline 5. Convenience of Use. & 4.48 & 0.48 & Good \\
\hline \multicolumn{1}{|c|}{ Average } & 4.18 & 0.46 & Good \\
\hline
\end{tabular}

\section{CONCLUSIONS}

This electronic book as developed according to the design principles of Borg's and Gall's theories [8] demonstrated that the target group found its quality to be good and they were very satisfied with using the electronic book. Therefore it is an appropriate device for use by the blind. It is very convenient to use, easy to carry around and the contents or texts can also be easily changed which creates fun and joy in learning. It also helps the users enjoy reading and develop a love of learning. The blind who use such a device can choose whatever they wanted to read, at any time in anyplace. It appears to be a very useful tool for education, as well as in self-development of the blind and their participation in society in the future.

\section{ACKNOWLEDGMENT}

S. Adisorn and S. Yuwadee thank The Bangkok School for The Blind for their support in the collection the data and help testing the device with blind students at the school.

Many thanks to assistant professor Dr. Surapon Boonlue, an instructor at King Mongkut's University of Technology Thonburi, for his advice and guidance regarding this research.

The authors thank Mr. Arthur Hermann for assistance checking the grammar and proof reading this paper.

\section{REFERENCES}

[1] B. Dujruedee, "The study of expectation and satisfaction of the people who have maimed eye sights towards the books with sound in Bangkok," Master's degree in journalism (Public Media), Journalism Faculty and Mass Communication, Thamasart University, Bangkok, Thailand, 2001.

[2] P. Somsong, Reading Writing and Typing of Braille Letters, Chongchareon Partnership Co., 1995, Bangkok, Thailand. 
[3] O. Chucheep, Psychology for Abnormal Children, Religious Printed Hose, Bangkok, Thailand, 1984, pp. 188,120.

[4] L. Nutthapon and S. Surut, "Thai-English Braille Recognition System," Bachelor's Degree in Faculty Education of science, Silpakorn University, Nakorn Pathom Province, Thailand, 2007, pp. 2-52.

[5] C. Siriwan, "The Making of Voice Book on Birds in Thailand for the people who have maimed eye sights, $4^{\text {th }}$ grade, School for the Blinds, Bangkok," Theory of Education Degree, Industrial Master's Degree in Educational Technology, Faculty of Education Industrial and Technology, King Mongkut's University of Technology Thonburi, Bangkok, Thailand, 2007, pp. 3-6.

[6] Foundation for the Blind, Thailand, Under Her Majesty the Queen's Patronage. (October 2009). The School for the Blind. [Online]. Available: http://www.blind.or.th/school/history01.htm, October 2009.

[7] R. Walter Borg and D. G. Merigith, "Educational Research," An Introduction, $5^{\text {th }}$ ed., New York: Longman Inc, 1989.

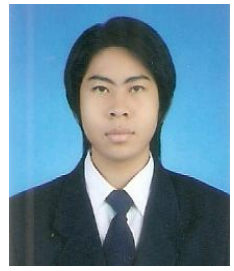

Adisorn Sirikham was born on November 12, 1981 in Ratchaburi Province, Thailand. He received Master of Engineering in Electrical, King Mongkut's University of Technology Thonburi, Thailand, 2007. He got the bachelor of engineering in electronics and telecommunication, King Mongkut's University of Technology Thonburi, Thailand, 2005.

$\mathrm{He}$ has been an Instructor at Rajamangala University of Technology Krungthep, Bangkok, Thailand, since 2007 - present. He teaches many subjects such as computer programming, digital circuit and logic design, and embedded system subjects. He has some publication papers for example: A. Sirikham and Y. Sae-ear, "A Design and Development System of Banknote Speaker Device for Blind People", The IASTED International conference Circuits and Systems, Hawaii, USA, August 23 - 25, 2010. He is interested research about educational technology for defective people.

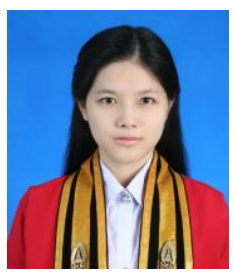

Yuwadee Sae-Ear was born on October 18, 1984 in Nongkhai Province, Thailand. She received master of science in industrial education, education technology, King Mongkut's University of Technology Thonburi, Thailand, 2010. She got the Bachelor of Science, computer science, King Mongkut's University of Technology Thonburi, Thailand, 2007.

She has been a freelance instructor, Bangkok, Thailand, since 2007 - present. She teaches many subjects such as computer multimedia and science. She has some publication papers for example: A Sirikham and Y. Sae-ear, "A Design and Development System of Banknote Speaker Device for Blind People", The IASTED International conference Circuits and Systems, Hawaii, USA, August 23 - 25, 2010. She is interested research about educational technology for defective people. 